\title{
Pigmentation of conjunctival melanoma recurrences and outcome
}

\author{
Niels J. Brouwer ${ }^{1}$ - Marina Marinkovic ${ }^{1} \cdot$ Gregorius P. M. Luyten $^{1} \cdot$ Carol L. Shields $^{2} \cdot$ Martine J. Jager $^{1}$
}

Received: 21 January 2019 /Revised: 9 April 2019 / Accepted: 26 April 2019 / Published online: 16 May 2019

(C) The Author(s) 2019

\begin{abstract}
Purpose In primary conjunctival melanoma $(\mathrm{CoM})$, one of the characteristics that is associated with an increased risk of metastases and death is a lack of tumour pigmentation. The aim of this study was to investigate whether the degree of pigmentation of CoM recurrences relates similarly to clinical outcome.

Methods A data set of 177 patients with a CoM recurrence from the Wills Eye Hospital (USA) and the Leiden University Medical Center (The Netherlands) was analysed. The relation between clinical tumour pigmentation of the recurrences, the characteristics of the primary lesions and clinical outcome was investigated.

Results In 117 (66\%) of 177 patients with a CoM recurrence, tumour pigmentation was known: 71 patients (61\%) had recurrences with low pigmentation. Primary lesions had low pigmentation in 39\% of cases, which is significantly different $(p=0.001)$. However, low tumour pigmentation of recurrences correlated with low tumour pigmentation of the primary lesion $(p<0.001)$. No association was observed between pigmentation of the recurrences and iris colour $(p=0.66)$. Low pigmentation of the recurrences was not significantly associated with an increased risk for metastases (HR 1.96, $p=0.12$ ) or death (HR 1.79, $p=0.27$ ), whereas primary tumours with low pigmentation did show a greater risk for metastases (HR 2.82, $p=0.016$ ) and death (HR 2.90, $p=0.037)$.

Conclusions CoM recurrences are more often lightly pigmented compared to primary lesions. A correlation exists between the degree of pigmentation of primary and recurrent lesions, but recurrences can appear with any degree of pigmentation. Unlike primary $\mathrm{CoM}$, the level of pigmentation of CoM recurrences is not related to metastasis or death.
\end{abstract}

Keywords Conjunctival melanoma $\cdot$ Pigmentation $\cdot$ Melanin $\cdot$ Oncology $\cdot$ Recurrences

\section{Introduction}

Conjunctival melanoma $(\mathrm{CoM})$ is a rare ocular malignancy that arises from melanocytes in the basal layer of the conjunctiva. It comprises about $5 \%$ of all ocular melanoma [1] and has an incidence of 0.6 to 0.8 per million in Caucasians $[2,3]$. CoM has a high recurrence rate, at $26-61 \%$ in 5 years [3-7]. Treatment for smaller CoM consists of local excision with adjuvant therapy (e.g. cryotherapy, topical chemotherapy and/or radiotherapy), while more extensive procedures such as orbital exenteration are required for larger or advanced CoM [8]. Despite treatment of the primary lesion, metastatic

Martine J. Jager

m.j.jager@lumc.nl

1 Department of Ophthalmology, Leiden University Medical Center, P.O. Box 9600, 2300 RC Leiden, The Netherlands

2 Ocular Oncology Service, Wills Eye Hospital, Thomas Jefferson University, Philadelphia, PA, USA disease can develop and can be fatal with a 10-year melanoma-related mortality of up to $29 \%[7,9]$.

To identify which mechanisms play a role in melanoma development and the formation of metastases, we recently studied tumour pigmentation in primary CoM [10]. A light tumour pigmentation was associated with a higher frequency of recurrences (HR 1.63, $p=0.043$ ), metastases (HR 2.48, $p=$ 0.004 ) and melanoma-related deaths (HR 2.60, $p=0.014$ ). It was furthermore noticed that iris colour and pigmentation of the primary tumour were associated $(p=0.021)$, as light tumour pigmentation was found more frequently in eyes with a light-coloured iris. Based on these findings, we hypothesised that the amount and type of melanin present in conjunctival melanocytes may play a role in the development and behaviour of CoM. Further, it may be that lightly coloured tumours are sometimes missed or misdiagnosed.

In clinical practice, it has been observed that CoM recurrences are frequently amelanotic, even though the original lesions can be pigmented (Fig. 1) [5]. This is clinically important as the recurrences may simulate other conjunctival 

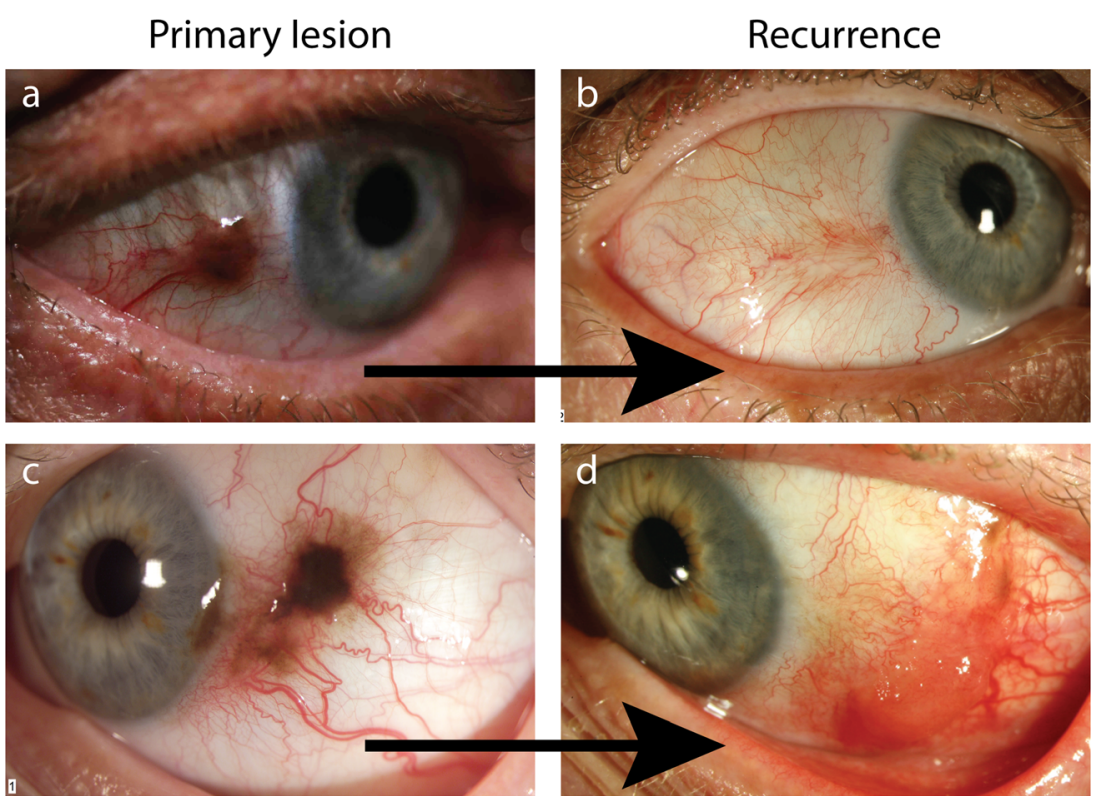

Fig. 1 Corresponding primary and recurrent lesions of conjunctival melanoma with different pigmentation. Both patient $1(\mathbf{a}, \mathbf{b})$ and patient $2(\mathbf{c}, \mathbf{d})$ presented with a primary lesion with high pigmentation and developed a recurrence with low pigmentation. Lightly pigmented recurrences may be difficult to detect or can be confused with other

disease, delaying proper diagnosis and treatment. Exemplary lesions that can appear as an amelanotic conjunctival mass are pyogenic granuloma, pinguecula or pterygium, or malignancies such as ocular surface squamous neoplasia or lymphoma $[5,11]$. It remains unclear how often CoM recurrences are amelanotic and how this relates to clinical outcome. As we demonstrated a relation between pigmentation of primary $\mathrm{CoM}$ and clinical behaviour, we wondered if pigmentation of recurrent CoM could also relate to outcome.

The aim of this study was to determine whether pigmentation of CoM recurrences resembles the corresponding primary lesion and whether pigmentation of $\mathrm{CoM}$ recurrences is related to clinical outcome.

\section{Methods}

A data set of 444 patients diagnosed with primary CoM from the Wills Eye Hospital (Philadelphia, USA) and the Leiden University Medical Center (Leiden, The Netherlands) was analysed. Patient and tumour characteristics of this combined set have been previously published [10]. In short, all patients had histopathologically confirmed CoM, the mean age of these patients was 59.5 years (SD 17.5), 51\% was female, the mean tumour thickness was $1.77 \mathrm{~mm}$ (SD 2.1) and 63\% of lesions were epibulbar. We identified 177 patients (40\%) who developed a local recurrence of CoM and reviewed the data of these patients, with an emphasis on tumour pigmentation. Tumour pigmentation of the primary lesions was ocular diseases. Patient 1 was treated for the primary CoM with local excision only. The recurrence developed after 9 months. Patient 2 was treated for the primary $\mathrm{CoM}$ with local excision and adjuvant brachytherapy. The recurrence developed after 6 years

classified clinically as 'high pigmentation' (i.e. 'pigmented') or 'low pigmentation' (i.e. 'non-pigmented/mixed'), based on the patient medical file and available clinical photographs [10]. Mixed lesions were categorised together with nonpigmented lesions as apparently parts of the lesion lost the ability to produce pigment. Tumour pigmentation of all known recurrences per patient (also determined clinically) was combined to one value of 'always high pigmentation' (i.e. if all recurrences were pigmented), 'always low pigmentation' (i.e. if all recurrences were non-pigmented/mixed) or 'variable' (i.e. if a combination of pigmented and nonpigmented recurrences occurred within the same patient). Iris colour was classified as 'light' (i.e. blue, green or grey) or 'dark' (i.e. hazel or brown), which reflects a division between low or high melanin content of iridal melanocytes [12]. Statistical analyses were performed using the SPSS software (v.23). Categorical data was analysed with the chi-square test or Fisher exact test. Numerical data was analysed with the Kruskal-Wallis test. Analyses of the development of metastasis or survival were performed with logistic regression and log rank (Kaplan-Meier) tests. $P$ values $<0.05$ were considered statistically significant.

\section{Results}

Of the 177 patients with a CoM recurrence, the pigmentation of the recurrent tumours was known in 117 (66\%) cases: 46 patients (39\%) had lesions in which the pigmentation was 
always high during follow-up, and 71 patients $(61 \%)$ had recurrences in which the pigmentation was always low (or variable) during follow-up. Of these 117 patients, mean age at diagnosis of the primary CoM was 64.5 years (SD 14.0). Mean age at the moment of the first recurrence was 67.9 years (SD 14.5). Between the patients with recurrences with consistently high, consistently low, or variable pigmentation, no statistically significant differences existed in age at diagnosis $(p=0.70)$ or age at first recurrence $(p=0.80)$ (Table 1$)$. There was no significant correlation between iris colour and tumour pigmentation of the recurrences $(p=0.66)$ (Table 1).

In 105 of the 117 patients with data on recurrent tumour pigmentation, pigmentation of the primary lesion was known: there were 64 cases $(61 \%)$ with high pigmentation and 41 cases $(39 \%)$ with low pigmentation. Compared to this percentage of primary lesions, recurrences were significantly more often lightly pigmented (61\% vs 39\%, $p=$ $0.001)$. Low tumour pigmentation of the primary lesion was significantly related to low tumour pigmentation of the recurrences $(p<0.001)$.

Primary CoM with low pigmentation was related to a greater risk for metastasis (HR 2.82; 95\%CI 1.21-6.56, $p=0.016$ ) and melanoma-related death (HR 2.90; 95\% CI $1.07-7.88, p=0.037)$. There was no statistically significant relation between recurrences with low pigmentation and an increased risk for metastasis (HR 1.96; 95\% CI $0.83-4.59, p=0.12$ ) and melanoma-related death (HR $1.79 ; 95 \%$ CI $0.64-5.00, p=0.27)$.

Using Kaplan-Meier analysis, patients with primary lesions with low pigmentation had a worse metastasis-free survival compared to patients with lesions with high pigmentation $(p=0.028)$. However, patients with recurrences with low or variable pigmentation had no different metastasis-free survival compared to those with recurrences with consistently high pigmentation ( $p=0.151)$ (Fig. 2).

In addition, we controlled for the pigmentation of the primary lesion by analysing the data separately for patients with either high or low pigmented primary CoM. This demonstrated that, also within sub groups, pigmentation of recurrences was not associated with metastasis or death (Fig. 3).

\section{Discussion}

In this study, we investigated the relationship between tumour pigmentation of CoM recurrences, tumour pigmentation of the corresponding primary lesions and clinical outcome. We found that the pigmentation of recurrent tumours was correlated with pigmentation of the primary lesion, and overall, recurrences were more frequently lightly pigmented. We found that pigmentation of recurrences did not relate to metastasis or death, while pigmentation of primary lesions did.
Clinical pigmentation depends on the amount and ratio of (dark-coloured) eumelanin and (lightly coloured) pheomelanin. These are two products of melanocytes with different biochemical characteristics: e.g. while eumelanin is protective against UV-radiation damage, pheomelanin is associated with the induction of genotoxic stress [13, 14]. Cutaneous melanocytes of dark-coloured skin contain more total melanin and relatively less pheomelanin compared to melanocytes of light-coloured skin [15], as do uveal melanocytes in dark versus light-coloured irises [12]. It is not known how the ratio of eumelanin and pheomelanin relates to tumour pigmentation in CoM, but it can be similarly expected that lesions with low pigmentation contain fewer total melanin and relatively more pheomelanin compared to lesions with high pigmentation.

As reported in our earlier study of a predominantly Caucasian population with CoM, $60 \%$ of all primary lesions were of high pigmentation and $40 \%$ were of low pigmentation [10]. This is significantly different from the percentages found in recurrent lesions of the same study population: 46 patients (39\%) had exclusively pigmented lesions during follow-up, and 71 patients $(61 \%)$ had non-pigmented or mixed lesions at some moment during follow-up. Therefore, as recurrences are more often lightly pigmented compared to primary lesions, the clinical observation that recurrences are frequently amelanotic is confirmed. This finding can be postulated through two different mechanisms: first, and most importantly, melanocytes of recurrent lesions may more often have lost the ability to produce pigment compared to primary lesions. One could hypothesise that this relates to an unfavourable melanocyte differentiation or unfavourable genetic status, which can be expected with melanoma that recurs. Second, and to a much lesser extent, the higher percentage of amelanotic recurrences compared to primary lesions may imply that amelanotic primary lesions are overlooked. Once a melanoma is demonstrated, clinicians will be more cautious in the follow-up of that patient, detecting possible amelanotic recurrences.

We hypothesised that tumour pigmentation in primary CoM may relate to genetic aberrations, and this could similarly determine pigmentation of recurrences [10]. Our clinical results show that recurrences often resemble their original lesion, not surprisingly as they share a genetic background and similar micro-environment, but they can also look different. In the 41 patients with a primary lesion with low pigmentation, $16(39 \%)$ developed recurrences with variable or high pigmentation. In the 64 patients with a primary lesion with high pigmentation, 27 (42\%) developed recurrences with variable or low pigmentation. It would be interesting to see how this relates to the genetic profile. It was demonstrated by Larsen et al. that BRAF mutations are found more frequently in nonpigmented compared to pigmented tumours [16]. Also, it was demonstrated by Larsen et al. that $B R A F$ mutations can differ 
Table 1 Tumour pigmentation of conjunctival melanoma recurrences in 117 cases, relationship to clinical factors and outcomes

\begin{tabular}{|c|c|c|c|c|}
\hline & \multicolumn{4}{|c|}{ Pigmentation of $\mathrm{CoM}$ recurrences } \\
\hline & $\begin{array}{l}\text { Always high } \\
\text { Cases (\%) }\end{array}$ & $\begin{array}{l}\text { Always low } \\
\text { Cases (\%) }\end{array}$ & $\begin{array}{l}\text { Variable } \\
\text { Cases (\%) }\end{array}$ & $p$ value \\
\hline Total & $46(39)$ & $51(44)$ & $20(17)$ & \\
\hline \multicolumn{5}{|l|}{ Pigmentation of the primary $\mathrm{CoM}^{\mathrm{a}}$} \\
\hline $\begin{array}{l}\text { Low pigmentation } \\
\text { High pigmenation }\end{array}$ & $\begin{array}{l}7(17) \\
37(58)\end{array}$ & $\begin{array}{l}25(61) \\
17(27)\end{array}$ & $\begin{array}{l}9(22) \\
10(16)\end{array}$ & $<0.001$ \\
\hline \multicolumn{5}{|l|}{ Iris colour } \\
\hline $\begin{array}{l}\text { Light } \\
\text { Dark }\end{array}$ & $\begin{array}{l}28(41) \\
18(38)\end{array}$ & $\begin{array}{l}31(45) \\
20(42)\end{array}$ & $\begin{array}{l}10(15) \\
10(21)\end{array}$ & 0.66 \\
\hline Age at primary CoM (mean, SD) & $64.4(15.5)$ & $63.8(13.6)$ & $66.6(11.9)$ & 0.70 \\
\hline Age at first recurrence (mean, SD) & $68.1(15.9)$ & $67.5(14.7)$ & $68.5(10.7)$ & 0.80 \\
\hline Number of recurrences per patient (mean, SD) & $2.2(2.8)$ & $1.9(1.0)$ & $5.4(5.5)$ & $<0.001$ \\
\hline \multicolumn{5}{|l|}{ Metastasis } \\
\hline $\begin{array}{l}\text { Yes } \\
\text { No }\end{array}$ & $\begin{array}{l}10(22) \\
36(78)\end{array}$ & $\begin{array}{l}18(35) \\
33(65)\end{array}$ & $\begin{array}{l}7(35) \\
13(65)\end{array}$ & 0.31 \\
\hline \multicolumn{5}{|l|}{ Melanoma-related death } \\
\hline $\begin{array}{l}\text { Yes } \\
\text { No }\end{array}$ & $\begin{array}{l}6(13) \\
40(87)\end{array}$ & $\begin{array}{l}10(20) \\
41(80)\end{array}$ & $\begin{array}{l}5(25) \\
15(75)\end{array}$ & 0.45 \\
\hline
\end{tabular}

${ }^{\text {a }}$ Of the 117 recurrences included in this study, in 12 cases, the pigmentation of the primary lesion was not known between precursor lesions and outgrowth of CoM [16]; this may be similar for the situation between primary CoM and recurrences. The $B R A F$ mutation status could be relevant for adjuvant treatment, as certain therapies target this specific mutation. Other mutations that have been reported in CoMbesides BRAF-include mutations in NRAS, KIT, TERT and $N F-1$ [17-19]. The relationship between these mutations and clinical tumour pigmentation has not been described. Griewank et al. reported an absent relation between histologically determined tumour pigmentation and the occurrence of TERT mutations in 38 cases of CoM [19], but this number may be too small for a final conclusion. Unfortunately, we could not determine the BRAF or other mutation status in our data set.

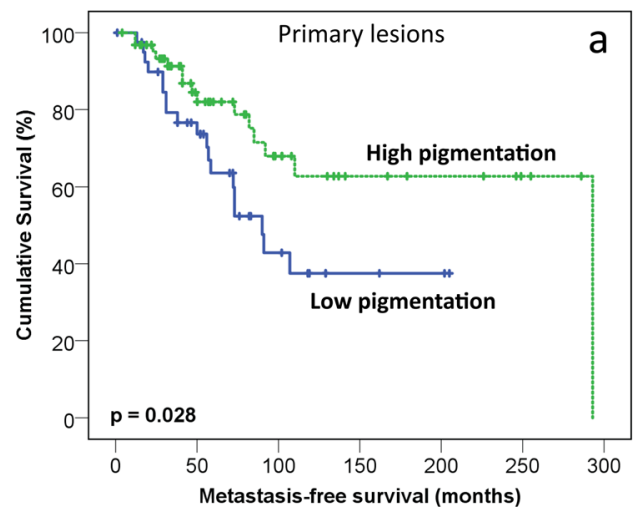

Fig. 2 Kaplan-Meier analysis of metastasis-free survival. a Patients are categorised by pigmentation of the primary lesion. A significant worse outcome is shown for patients with low tumour pigmentation $(n=41)$ compared to high pigmentation $(n=64, p=0.028)$. b The same group
While the amount of pigmentation of primary CoM is related to metastasis and survival, this was not the case for pigmentation of recurrences. We hypothesise that metastases often have an early origin in patients with $\mathrm{CoM}$, being more related to the primary lesion than to subsequent local recurrences. This would be in line with tumour dormancy as thought to exist in metastases of uveal and cutaneous melanoma [20] and is in line with some observations of CoM recurrence or metastasis years after margin-free excision, implying that cells have spread already prior to primary treatment [21, 22]. In addition, the finding that pigmentation of recurrences is not related to clinical outcome may indicate that while primary amelanotic tumours may occasionally be excised with too small margins, recurrences are treated more heavily and

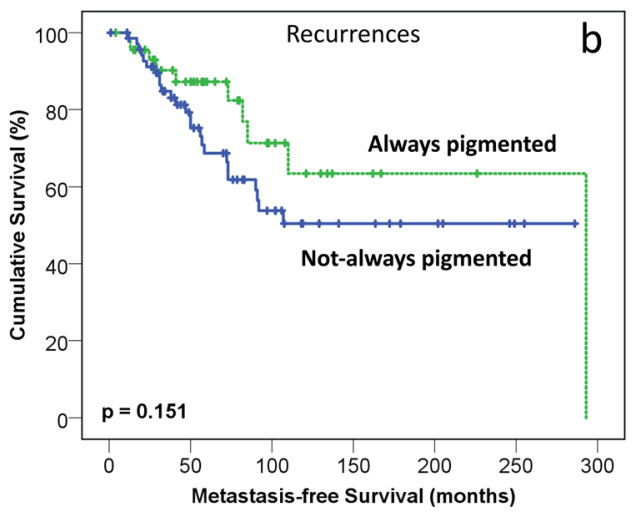

of patients is depicted, but is now categorised by the pigmentation of their recurrences. Outcome is not significantly different for those with recurrences with always high pigmentation $(n=46)$ compared to those with always low (or variable) pigmentation $(n=71, p=0.151)$ 
Fig. 3 Flow chart of patients with a CoM recurrence and known pigmentation of both the primary and recurring lesions. Patients are first divided by the pigmentation of the primary lesion and second by the pigmentation of the recurrences. Outcome is reported for each subgroup. While metastasis and death are significantly associated with pigmentation of the primary lesion (worse for lesions with low pigmentation), pigmentation of recurrences is not further associated with outcome

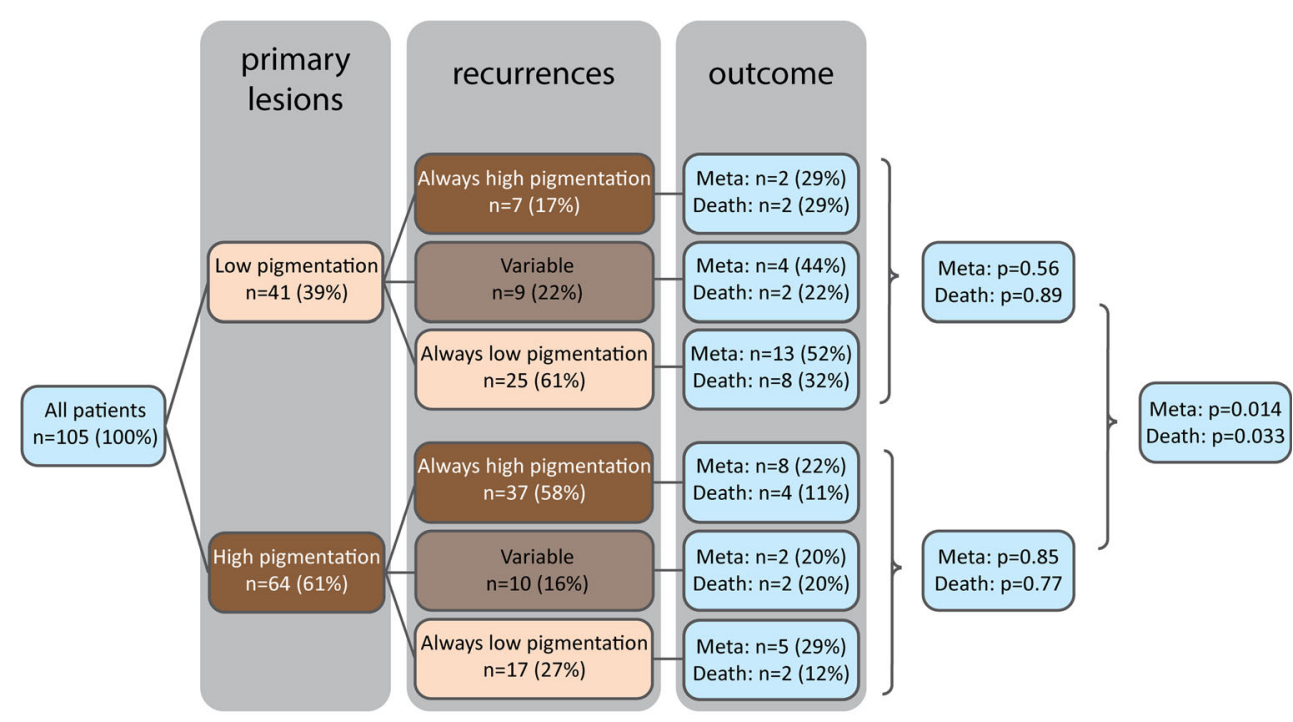

For primary lesions with low vs high pigmentation, the overall metastasis rate was $n=19(46 \%)$ vs $n=15(23 \%), p=0.014$, and the overall number of melanoma-related death was $n=12(29 \%)$ vs $n=8(13 \%), p=0.033$, respectively. adequately as clinicians will be more aware. Based on our results, we do not advise to treat CoM recurrences differently based on their pigmentation. It is emphasised to look for any aberrant lesion in an eye with previous CoM and to inform patients that recurrences may appear differently.

A strength of this study is the large number of CoM recurrences that were included. While primary CoM has been described to a larger extent, data on recurrences is much more uncommon. As our analysis was performed on a data set with previously recorded clinical parameters, some limitations apply due to the availability of data. Unfortunately, data on tumour pigmentation was not available for all patients. We do not believe that this has biased the results, as the recording seems to be an administrative matter, with gaps in data being random, and is not related to the pigmentation status. Apart from this, it may be that amelanotic recurrences were overlooked in patients and that the actual percentage of low pigmentation recurrences is even higher than currently reported.

A potential bias was introduced by categorising the pigmentation of all known recurrences per patient into one value. By definition, the group of patients with 'variable' pigmentation has multiple recurrences, in contrast to the groups of 'always high pigmentation' or 'always low pigmentation' that also include patients with only one recurrence. We do not believe that this has influenced our conclusion, as the expected bias would overestimate an effect for low pigmentation/ variable lesions on metastasis and death - and we detected no significant effect at all.

One might wonder whether the initial treatment of CoM relates to the pigmentation of recurrences. The majority of patients who were included in this study received excision with cryotherapy as initial treatment for the primary CoM.
Other treatments included excision alone, topical chemotherapy, brachytherapy (using various devices) and external radiation. We do not feel that our data allows for a thorough analysis of all the various treatment combinations to adequately answer this question.

\section{Conclusion}

In short, we demonstrated that $\mathrm{CoM}$ recurrences are more frequently lightly pigmented compared to primary lesions. Pigmentation of the original lesion corresponds to the pigmentation of a recurrence, but deviations occur, and clinicians should be wary of any aberrant lesion in an eye with previously diagnosed CoM. In contrast to primary CoM, no association was observed between tumour pigmentation of recurrences and clinical outcome. Future research should explore the genetic profile of primary lesions versus recurrences, as they may differ and this may be relevant for treatment.

Funding NJB received an $\mathrm{MD} / \mathrm{PhD}$ programme grant from the LUMC. The sponsor or funding organisation had no role in the design or conduct of this research.

\section{Compliance with ethical standards}

Conflict of interest The authors declare that they have no conflict of interest.

Ethical approval All procedures performed were in accordance with the ethical standards of the institutional and/or national research committee and with the 1964 Helsinki declaration and its later amendments or comparable ethical standards.

Informed consent For this type of study, formal consent is not required. 
Open Access This article is distributed under the terms of the Creative Commons Attribution 4.0 International License (http:// creativecommons.org/licenses/by/4.0/), which permits unrestricted use, distribution, and reproduction in any medium, provided you give appropriate credit to the original author(s) and the source, provide a link to the Creative Commons license, and indicate if changes were made.

\section{References}

1. Isager P, Engholm G, Overgaard J, Storm H (2006) Uveal and conjunctival malignant melanoma in Denmark 1943-97: observed and relative survival of patients followed through 2002 . Ophthalmic Epidemiol 13:85-96. https://doi.org/10.1080/ 09286580600553330

2. Triay E, Bergman L, Nilsson B, All-Ericsson C, Seregard S (2009) Time trends in the incidence of conjunctival melanoma in Sweden. Br J Ophthalmol 93:1524-1528. https://doi.org/10.1136/bjo.2009. 157933

3. Tuomaala S, Eskelin S, Tarkkanen A, Kivela T (2002) Populationbased assessment of clinical characteristics predicting outcome of conjunctival melanoma in whites. Invest Ophthalmol Vis Sci 43: 3399-3408

4. Brouwer NJ, Marinkovic M, van Duinen SG, Bleeker JC, Jager MJ, Luyten GPM (2018) Treatment of conjunctival melanoma in a Dutch referral centre. Br J Ophthalmol 102:1277-1282. https:// doi.org/10.1136/bjophthalmol-2017-311082

5. Shields CL (2000) Conjunctival melanoma: risk factors for recurrence, exenteration, metastasis, and death in 150 consecutive patients. Trans Am Ophthalmol Soc 98:471-492

6. Shields CL, Markowitz JS, Belinsky I, Schwartzstein H, George NS, Lally SE, Mashayekhi A, Shields JA (2011) Conjunctival melanoma: outcomes based on tumor origin in 382 consecutive cases. Ophthalmology 118:389-395 e381-382. https://doi.org/10.1016/j. ophtha.2010.06.021

7. Missotten GS, Keijser S, De Keizer RJ, De Wolff-Rouendaal D (2005) Conjunctival melanoma in the Netherlands: a nationwide study. Invest Ophthalmol Vis Sci 46:75-82. https://doi.org/10. 1167/iovs.04-0344

8. Wong JR, Nanji AA, Galor A, Karp CL (2014) Management of conjunctival malignant melanoma: a review and update. Expert Rev Ophthalmol 9:185-204. https://doi.org/10.1586/17469899. 2014.921119

9. Werschnik C, Lommatzsch PK (2002) Long-term follow-up of patients with conjunctival melanoma. Am J Clin Oncol 25:248-255

10. Brouwer NJ, Marinkovic M, Luyten GPM, Shields CL, Jager MJ (2019) Lack of tumour pigmentation in conjunctival melanoma is associated with light iris colour and worse prognosis. Br J Ophthalmol 103:332-337. https://doi.org/10.1136/bjophthalmol2018-312018

11. Shields CL, Chien JL, Surakiatchanukul T, Sioufi K, Lally SE, Shields JA (2017) Conjunctival tumors: review of clinical features, risks, biomarkers, and outcomes - the 2017 J. Donald M. Gass Lecture. Asia Pac J Ophthalmol (Phila) 6:109-120. https://doi. org/10.22608/APO.201710
12. Wakamatsu K, Hu DN, McCormick SA, Ito S (2008) Characterization of melanin in human iridal and choroidal melanocytes from eyes with various colored irides. Pigment Cell Melanoma Res 21:97-105. https://doi.org/10.1111/j.1755-148X. 2007.00415.x

13. Ito S, Wakamatsu K (2003) Quantitative analysis of eumelanin and pheomelanin in humans, mice, and other animals: a comparative review. Pigment Cell Res 16:523-531

14. Mitra D, Luo X, Morgan A, Wang J, Hoang MP, Lo J, Guerrero CR, Lennerz JK, Mihm MC, Wargo JA, Robinson KC, Devi SP, Vanover JC, D’Orazio JA, McMahon M, Bosenberg MW, Haigis KM, Haber DA, Wang Y, Fisher DE (2012) An ultravioletradiation-independent pathway to melanoma carcinogenesis in the red hair/fair skin background. Nature 491:449-453. https://doi.org/ 10.1038/nature11624

15. De Leeuw SM, Smit NP, Van Veldhoven M, Pennings EM, Pavel S, Simons JW, Schothorst AA (2001) Melanin content of cultured human melanocytes and UV-induced cytotoxicity. J Photochem Photobiol B 61:106-113

16. Larsen AC, Dahl C, Dahmcke CM, Lade-Keller J, Siersma VD, Toft PB, Coupland SE, Prause JU, Guldberg P, Heegaard S (2016) BRAF mutations in conjunctival melanoma: investigation of incidence, clinicopathological features, prognosis and paired premalignant lesions. Acta Ophthalmol 94:463-470. https://doi.org/ 10.1111/aos.13007

17. Scholz SL, Cosgarea I, Susskind D, Murali R, Moller I, Reis H, Leonardelli S, Schilling B, Schimming T, Hadaschik E, Franklin C, Paschen A, Sucker A, Steuhl KP, Schadendorf D, Westekemper H, Griewank KG (2018) NF1 mutations in conjunctival melanoma. Br J Cancer 118:1243-1247. https://doi.org/10.1038/s41416-0180046-5

18. Beadling C, Jacobson-Dunlop E, Hodi FS, Le C, Warrick A, Patterson J, Town A, Harlow A, Cruz F 3rd, Azar S, Rubin BP, Muller S, West R, Heinrich MC, Corless CL (2008) KIT gene mutations and copy number in melanoma subtypes. Clin Cancer Res 14:6821-6828. https://doi.org/10.1158/1078-0432.CCR-080575

19. Griewank KG, Murali R, Schilling B, Scholz S, Sucker A, Song M, Susskind D, Grabellus F, Zimmer L, Hillen U, Steuhl KP, Schadendorf D, Westekemper H, Zeschnigk M (2013) TERT promoter mutations in ocular melanoma distinguish between conjunctival and uveal tumours. Br J Cancer 109:497-501. https://doi.org/ $10.1038 /$ bjc. 2013.312

20. Ossowski L, Aguirre-Ghiso JA (2010) Dormancy of metastatic melanoma. Pigment Cell Melanoma Res 23:41-56. https://doi. org/10.1111/j.1755-148X.2009.00647.x

21. Paridaens AD, McCartney AC, Lavelle RJ, Hungerford JL (1992) Nasal and orbital recurrence of conjunctival melanoma 21 years after exenteration. Br J Ophthalmol 76:369-371

22. Brouwer NJ, Genders SW, Marinkovic M, van Duinen SG, Jager MJ, Luyten GPM (2018) Two late recurrences of conjunctival melanoma. Ocul Oncol Pathol. https://doi.org/10.1159/000494978

Publisher's note Springer Nature remains neutral with regard to jurisdictional claims in published maps and institutional affiliations. 